\title{
Spectrum of Clinical Manifestations in Turkish Patients with Williams-Beuren Syndrome: A Monocentric Study
}

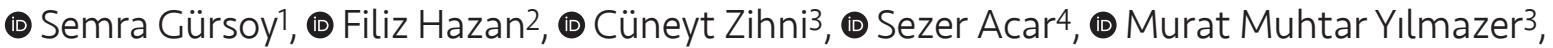 \\ (1) Timur Meşe3, (1) Behzat Özkan4
}

1University of Health Sciences Turkey, İzmir Dr. Behçet Uz Child Disease and Pediatric Surgery Training and Research Hospital, Clinic of Pediatric Genetics, İzmir, Turkey

2University of Health Sciences Turkey, İzmir Dr. Behçet Uz Child Disease and Pediatric Surgery Training and Research Hospital, Clinic of Medical Genetics, Izmir, Turkey

${ }^{3}$ University of Health Sciences Turkey, İzmir Dr. Behçet Uz Child Disease and Pediatric Surgery Training and Research Hospital, Clinic of Pediatric Cardiology, İzmir, Turkey

4University of Health Sciences Turkey, İzmir Dr. Behçet Uz Child Disease and Pediatric Surgery Training and Research Hospital, Clinic of Pediatric Endocrinology, İzmir, Turkey

\begin{abstract}
Aim: Williams-Beuren syndrome, which is characterized by dysmorphic facial features, cardiovascular findings, intellectual disability, endocrine abnormalities and a typical cognitive profile, is caused by a microdeletion in the 7q11.23 region. In this study, we aimed to evaluate the dysmorphic and clinical manifestations of patients with Williams-Beuren syndrome.

Materials and Methods: We retrospectively collected data from 27 Turkish patients who had clinically and genetically confirmed WilliamsBeuren syndrome. Their multisystemic manifestations, demographic data and dysmorphic facial features were recorded.

Results: All patients had the characteristic facial phenotype. The most frequent dysmorphic facial features were periorbital fullness, short nose, broad nasal tip and wide mouth. Aortic stenosis (59.2\%) and pulmonary stenosis (37\%) were the most common cardiac findings. Short stature (25.9\%), idiopathic central precocious puberty (7.4\%), hypothyroidism (congenital, non-congenital or subclinical) (40.7\%) and hypercalcemia (3.7\%) were the major endocrine manifestations in the patients. Genitourinary abnormalities were detected in 6 patients. All patients had some degree of intellectual disability; most of the patients (62.9\%) had mild intellectual disability. Additionally, behavioral problems were frequently detected and the most common abnormality was overfriendliness (77.7\%). Renal abnormalities (double collecting system, bladder diverticula and renal calculi) were also detected.

Conclusion: Dysmorphic facial features, which have a crucial role in the diagnosis of Williams-Beuren syndrome, should be assessed in suspected patients with supravalvular aortic stenosis and concomitant intellectual disability in order to make an early diagnosis. It should be kept in mind that endocrine abnormalities, musculoskeletal, neurologic and psychiatric manifestations are also common in patients with Williams-Beuren syndrome, necessitating a multidisciplinary approach.
\end{abstract}

Keywords: Williams-Beuren syndrome, 7q11.23 deletion, supravalvular aortic stenosis, pulmonary stenosis, intellectual disability

\footnotetext{
Address for Correspondence

Semra Gürsoy, University of Health Sciences Turkey, Izmir Dr. Behçet Uz Child Disease and Pediatric Surgery Training and Research Hospital, Clinic of Pediatric Genetics, izmir, Turkey
} 


\section{Introduction}

Williams-Beuren syndrome [(WBS), OMIM: 194050] is a congenital disorder that has a prevalence of $1 / 7,500$ $1 / 20,000$ in newborns (1). This syndrome is characterized by dysmorphic facial features, cardiovascular disorders [supravalvular aortic stenosis (SVAS), elastin arteriopathy, peripheral pulmonary stenosis], intellectual disability, endocrine abnormalities (hypercalcemia, hypercalciuria, hypothyroidism, and precocious puberty) and a typical cognitive profile with over-friendly behavior (2). The typical facial features include broad forehead, bitemporal narrowing, periorbital fullness, strabismus, short nose, broad nasal tip, malar flattening, thick vermilion of the upper and lower lips, wide mouth, small jaw and large ear lobes. Hypotonicity is frequently detected in infants with WBS who typically have hyperextensible joints and delayed motor development. Connective tissue abnormalities including inguinal/umbilical hernia, bowel/bladder diverticula and rectal prolapse can also be observed. While penetrance is $100 \%$, expression of the phenotypic features is variable in patients with WBS (3).

Williams-Beuren syndrome is caused by the deletion of approximately 1.5-1.8 megabase pairs on chromosome 7q11.23. It encompasses 26-28 genes including elastin (ELN). The ELN gene encodes a protein which is one of the two components of elastic fibers. Elastic fibers are important extracellular matrix macromolecules that provide elasticity and resilience to tissues and organs such as the arteries, heart, lungs, skin and ligaments. The atypical deletions are uncommon (2-5\%) and range from $200 \mathrm{~Kb}$ to $2.5 \mathrm{Mb}$. The deletion size usually correlates with the phenotype (4-6). Genomic testing methods which determine the copy number of sequences can include chromosomal microarray or targeted deletion analysis by fluorescence in situ hybridization (FISH) (3). Most deletions occur de novo; but rare instances of parent-to-child transmission have been reported in patients with WBS (7).

The aim of this monocentric study was to describe the dysmorphic and clinical manifestations in a cohort of Turkish patients with WBS.

\section{Materials and Methods}

Twenty-seven patients with clinically and genetically confirmed WBS were included in this study. All patients were examined at the Department of Pediatric Genetics and Medical Genetics of University of Health Sciences Turkey, Dr. Behçet Uz Child Disease and Pediatric Surgery Training and Research Hospital, İzmir, Turkey between June 2012 and July
2020. Clinical data including prenatal signs, demographic features, and age at the time of diagnosis were collected from the clinical records and by parental interviews. The growth parameters of the patients were evaluated in accordance with the specific growth charts for WBS (8). Additionally, the dysmorphic facial features, laboratory test results and imaging results were noted. After diagnosis, all patients were included in a multi-specialist follow-up protocol.

All patients had a typical chromosomal 7q11.23 deletion which was detected by FISH analysis. We excluded those patients who were not genetically diagnosed. The local Ethics Committee approved the study (date: 24.09.2020, number: 2020/13-8), and written informed consent was obtained from all individuals involved. The study was conducted in accordance with the Helsinki Declaration.

\section{Statistical Analysis}

Statistical analyses were performed using IBM SPSS Statistics for Windows, Version 23.0. (IBM Corp. Armonk, NY). Data is presented with descriptive statistics (median with $25^{\text {th }}-75^{\text {th }}$ percentiles for continuous variables; frequency and percentage for categorical variables).

\section{Results}

The main facial features and clinical findings of the 27 patients (18 males, 9 females) are summarized in Table I. The median age at the time of diagnosis was 4 years (1-8). The median follow-up period of the patients was 5 years (5-8). Ten patients (37\%) were diagnosed before the age of 2. The median birth weight of the patients was $2.75 \mathrm{~kg}$ (2.253.1). All patients had several types of the characteristic facial features of WBS (Table I). The most common facial findings

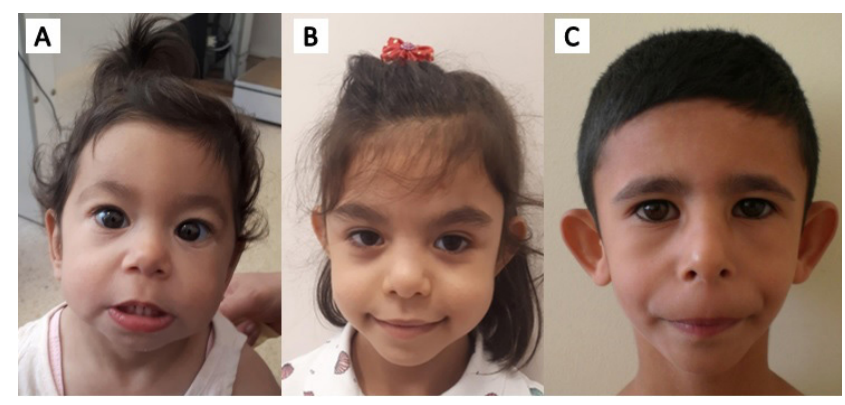

Figure 1. Dysmorphic facial findings of some of the study patients. A: Broad forehead, periorbital fullness, epicanthal fold, short nose, broad nasal tip, full cheeks, wide mouth, long philtrum and small jaw in a 1.5-year-old patient. B: Periorbital fullness, broad forehead, full cheeks, short nose, broad nasal tip and wide mouth in a 7-year-old patient. C: Broad forehead, periorbital fullness, short nose, broad nasal tip, wide mouth, long and smooth philtrum and small jaw in an 8-year-old patient 
Table I. Clinical manifestations of the patients with Williams Beuren syndrome

\begin{tabular}{|l|l|}
\hline Clinical findings & $\mathbf{n}(\%)$ \\
\hline Sex & \multicolumn{2}{|l|}{} \\
\hline Male & $18(66.6)$ \\
Female & $9(33.3)$ \\
\hline Prematurity & $5(18.5)$ \\
\hline Small for gestational age & $9(33.3)$ \\
\hline Dysmorphic features & $27(100)$ \\
Periorbital fullness & $27(100)$ \\
Short nose & $27(100)$ \\
Broad nasal tip & $27(100)$ \\
Wide mouth & $27(100)$ \\
Long philtrum & $25(92.5)$ \\
Full cheeks & $23(85.1)$ \\
Small jaw & $22(81.4)$ \\
Broad forehead & $22(81.4)$ \\
Epicanthal fold & $17(62.9)$ \\
Large ear lobes & $13(48.1)$ \\
\hline Short stature & $5(18.5)$ \\
\hline Cardiovascular findings & $24(88.8)$ \\
\hline Endocrinologic and genitourinary findings & $19(70.3)$ \\
Hypothroidism & $11(40.7)$ \\
Hypercalcemia & $1(3.7)$ \\
Precocious puberty & $2(7.4)$ \\
Genital abnormalities & $4(14.8)$ \\
Urinary tract abnormalities & $2(7.4)$ \\
\hline Ocular findings & $12(44.4)$ \\
\hline Connective tissue and skeletal & $27(100)$ \\
\hline abnormalities & $14(51.8)$ \\
\hline Intellectual disability & $27(100)$ \\
Mild & $17(62.9)$ \\
Moderate & $8(29.6)$ \\
Severe & $1(3.7)$ \\
Global developmental delay & $1(3.7)$ \\
\hline Behavioral traits & $25(92.5)$ \\
Overfriendliness & $21(77.7)$ \\
Attention deficit disorder & $7(25.9)$ \\
Phobia & $7(25.9)$ \\
Autistic features & $4(14.8)$ \\
Specisific learning disability & $1(3.7)$ \\
\hline Epilepsy & $2(7.4)$ \\
\hline Total & \\
\hline
\end{tabular}

were periorbital fullness, long philtrum, short nose, broad nasal tip and wide mouth (Figure 1). The median weight of the patients was $25 \mathrm{~kg}$ (7-73) and the median height was $126 \mathrm{~cm}$ (73-164) during the final evaluation. Weight over 2 standard deviation score (SDS) was detected in six patients and the other patients were between the normal ranges. Short stature below 2 SDS was observed in 5 individuals and one of them was also small for gestational age (SGA). In two patients with insufficient annual height velocity during follow-up, growth hormone stimulation tests (Clonidine)
Table II. Echocardiographic results of the patients with Williams-Beuren syndrome

\begin{tabular}{|l|l|}
\hline Echocardiographic findings & $\mathbf{n}(\%)$ \\
\hline Aortic stenosis & $16(59.2)$ \\
Valvular & $1(3.7)$ \\
Supravalvular & $15(55.5)$ \\
\hline Pulmonary stenosis & $10(37)$ \\
$\begin{array}{l}\text { Valvular } \\
\text { Supravalvular }\end{array}$ & $3(11.1)$ \\
Valvular + Supravalvular & $1(3.7)$ \\
Peripheral & $2(7.4)$ \\
\hline Aortic stenosis + Pulmonary & $4(14.8)$ \\
\hline stenosis & $6(22.2)$ \\
\hline Mitral regurgitation (mild) & $3(11.1)$ \\
\hline Mitral valve prolapse & $3(11.1)$ \\
\hline Aortic regurgitation (mild) & $2(7.4)$ \\
\hline Pulmonary hypertension & $1(3.7)$ \\
\hline Bicuspid aortic valve & $1(3.7)$ \\
\hline Ventricular septal defect & $1(3.7)$ \\
\hline No cardiac abnormality & $3(11.1)$ \\
\hline Total & $27(100)$ \\
\hline
\end{tabular}

were performed and adequate growth hormone response $(>10 \mathrm{ng} / \mathrm{mL}$ ) was obtained. Ultimately, growth hormone deficiency could not be demonstrated in any of the patients.

Cardiologic evaluation was performed in all patients. Three participants did not have any cardiac abnormalities. In the remaining patients, aortic stenosis and pulmonary stenosis were the most common features. Furthermore, three patients had mild mitral regurgitation; two of them were associated with mitral valve prolapsus. The echocardiographic findings of the patients are given in Table II. More than one cardiac abnormality was detected in 12 patients. Two patients with SVAS and one patient with ventricular septal defect underwent cardiac surgery. Balloon valvuloplasty was performed in two patients due to valvular pulmonary stenosis. Additionally, the severity of peripheral or supravalvular pulmonary stenosis was decreased in two patients during echocardiographic follow-up.

Connective tissue abnormalities and musculoskeletal findings were present in 14 patients (51.8\%) (Table I) and 10 of them had uni- or bilateral inguinal hernia. Additionally, 4 patients had a variable degree of thoracolumbar scoliosis, and torticollis was detected in a one-year-old patient.

Hypothyroidism was detected in 11 (40.7\%) cases; 2 of them had congenital primary hypothyroidism, 4 of them had non-congenital primary hypothyroidism requiring 
L-thyroxine treatment, and 5 of them had subclinical hypothyroidism not requiring any treatment. One of these patients also had vitamin D deficiency. Chronic constipation was present in 5 patients and 4 of these also had hypothyroidism. Additionally, a single patient had asymptomatic hypercalcemia. Idiopathic central precocious puberty was diagnosed (both with Tanner stage 2 and $>5.0$ IU/L peak Luteinizing-hormone levels after Luteinizinghormone releasing hormone stimulation) in two patients (8.5-year-old male and 7-year-old female) who were treated with gonadotropin-releasing hormone. The genital abnormalities included unilateral cryptorchidism $(n=2)$, penile hypospadias $(n=1)$ and webbed penis $(n=1)$, which were not attributed to any endocrine/hormonal pathology (Table I). Double collecting system and bladder diverticula were found in one female patient. Additionally, renal calculi were detected in another patient.

Hearing tests were performed in all patients and a mild hearing loss was detected in one male patient. Ocular manifestations were present in approximately half of the patients (Table I). The most common findings were strabismus $(n=5,18.5 \%)$ and stellate pattern of the iris $(n=3,11.1 \%)$. Myopia $(n=1)$, hyperopia $(n=2)$, astigmatism $(n=1)$ and glaucoma $(n=1)$ were also detected.

All patients had some degree of intellectual disability and one of them also had global developmental delay (Table I). Almost all of the patients had several types of behavioral problems (Table I). One patient, who had mild intellectual disability, also had a specific learning disability. Echolalia was remarkable in one patient with global developmental delay and autistic features. Epilepsy was detected in two patients and Chiari malformation type 1 was found in two other patients.

\section{Discussion}

In this monocentric study, we evaluated the dysmorphic features and clinical abnormalities in a cohort of 27 Turkish patients with WBS, which is a congenital genetic disorder. The microdeletion at 7q11.23 involves the gene coding for elastin, which is an important protein in the composition of elastic fibers of connective tissue. This gene may explain some phenotypic characteristics and disorders present in WBS such as connective tissue abnormalities and cardiovascular diseases.

The majority ( $80 \%)$ of patients with WBS have structural cardiovascular abnormalities typically related to arterial stenosis (9). These cardiovascular disorders are usually associated with increased morbidity and mortality (10). Patients with combined SVAS and pulmonary stenosis or coronary artery stenosis may develop biventricular hypertrophy and hypertension, which increases the risk of myocardial ischemia, arrhythmias and sudden death $(10,11)$. The incidence of sudden death in one cohort of 293 patients with WBS was 1/1,000 patient years, which is 25 to 100 times higher than the age-matched population (12). Bruno et al. (13) reported that SVAS was the most frequent malformation representing $71 \%$ of cases, and the incidence of pulmonary stenosis at the valvular level was $11 \%$. Pulmonary artery stenosis was the other common finding and its incidence was reported to be approximately $40 \%$ in patients. Of those patients with cardiac anomalies, $34.5 \%$ had a single defect and $65.5 \%$ had multiple defects $(14,15)$. In the current study, cardiovascular anomalies were evident in most of our patients (88\%). Consistent with the literature, the most common findings were aortic and pulmonary stenosis. In 6 patients, SVAS was accompanied by pulmonary stenosis. A single cardiac abnormality was detected in half of the patients with established cardiac findings. Previously, it has been reported that peripheral pulmonary stenosis is associated with a good long-term prognosis (14). In our study, 10 patients had pulmonary stenosis and 2 of them (one peripheral, one supravalvular) showed improvement during follow-up. Pulmonary balloon valvuloplasty was performed in two other patients with valvular pulmonary stenosis.

The phenotypical traits in WBS patients are well characterized, but become more evident with increasing age; therefore, the probability of finding a 7q11.23 deletion is greater in older individuals $(16,17)$. Additionally, patients with mild or insignificant cardiac involvement are older at the time of diagnosis compared to patients with SVAS or severe cardiac symptoms (15). In our study, all of the patients had typical facial characteristics, but only 10 patients (37\%) had been diagnosed before the age of 2 . Eight of these patients had more than one cardiac finding and 6 of them had both aortic and pulmonary stenosis. In the remaining 17 patients who were diagnosed after 2 years of age, aortic stenosis and pulmonary stenosis were detected in 9 and 2 patients, respectively. Additionally, 2 patients had mild mitral regurgitation due to mitral valve prolapsus and 1 patient had pulmonary hypertension. Three patients $(2.5,5$ and 10 years of age at the time of diagnosis) did not have any cardiac abnormalities. On the basis of these findings, we may suggest that although SVAS is the most common cardiac abnormality in patients with WBS, SVAS accompanied by pulmonary stenosis may be a stronger indicator for this disease. Furthermore, in patients with suspected SVAS and intellectual disability, assessment of characteristic facial features may enable the early detection of the disease. 
Recently, endocrine abnormalities have been reported in detail in patients with WBS. Although pre- and postnatal growth retardation is common in this syndrome, growth hormone deficiency has not been considered as a major cause. This may be attributed to restricted prenatal growth, failure to thrive in infancy or restricted growth in childhood. In a previous study, the frequency of short stature was reported to be $33 \%$ at preschool ages and $67 \%$ at school ages in patients with WBS. About $50 \%$ to $60 \%$ of the patients with WBS reach a final adult height below their target height range $(18,19)$. The other endocrine abnormality, congenital hypothyroidism, is rare, but subclinical hypothyroidism occurs in $31 \%$ of patients, and occurs more frequently in children than in adults (20). Additionally, precocious puberty is common in WBS and true precocious puberty has been reported in $3-18 \%$ of the patients (21). Hypercalcemia was also reported in 5-50\% of individuals with WBS. It is usually mild but it may present with vomiting, constipation, irritability and muscle cramps (22). In the present study, short stature was detected in 5 patients and one of them had SGA. Hypothyroidism (congenital/non-congenital primary or subclinical hypothyroidism) and central precocious puberty were detected in $11(40.7 \%)$ and 2 (7.4\%) patients, respectively. Furthermore, hypercalcemia was detected in a single asymptomatic patient. Endocrine abnormalities are not uncommon causes of morbidity in patients with WBS; therefore, close monitoring and follow-up are needed for the management and the prediction of the prognosis of these endocrine dysfunctions.

The risk of external genital abnormalities, renal and urinary tract structural abnormalities (renal ectopia, agenesis, hypoplasia, duplication, horseshoe kidney, hydronephrosis, and vesicoureteral reflux) in WBS cases were demonstrated to be more common (up to 73\%) than the normal population (23). In this study, 4 (14.8\%) cases had external genital abnormalities and 2 (7.4\%) cases had renal and urinary tract structural abnormalities. However, none of them contributed to any endocrine/hormonal pathology. The relatively low frequency of urogenital anomalies in our study may be explained by the low number of patients and the absence of further investigations such as voiding cystourethrogram or dimercaptosuccinic acid scintigraphy.

Musculoskeletal manifestations can be commonly observed in WBS. Atypical posture and exaggerated or abnormal spinal curvatures are also a frequent finding in patients with WBS. Lordosis was described in $38 \%$ of infants and $90 \%$ of adolescents and young adults. Additionally, while kyphosis was reported in $10-21 \%$ of patients, scoliosis was detected in $12 \%$ to $20 \%$ of patients (24). In a recent study, Damasceno et al. (25) identified scoliosis in 34\% of their patients. In the present study, thoracolumbar scoliosis was detected in 4 patients (14.8\%), whereas neither lordosis nor kyphosis was observed in any cases. Additionally; torticollis, which is a rare musculoskeletal abnormality in WBS, was detected in a one-year-old male patient. Physical therapy was performed in all of these patients. These musculoskeletal features are not specific to WBS, but they should be kept in mind and assessed when necessary to prevent disease progression.

Seventy-five percent of patients with WBS have intellectual disability, which is usually mild. The cognitive profile of these patients is distinctive. It consists of good verbal short-term memory and language while visuospatial constructive cognition is highly impaired (26). Furthermore, patients with WBS have a typical personality profile which includes overfriendliness, excessive empathy, attention problems and social disinhibition. Emotional regulation, perseveration, and specific phobias can also be observed. Some patients have overlapping symptoms with the autism spectrum disorder $(27,28)$. In the present study, all patients had intellectual disability, but most of them to a mild degree (62.9\%). Overfriendliness (77.7\%) was the most common personality profile which is consistent with the current literature. Additionally, 4 patients had autistic features. While 3 of these patients also had moderate or severe intellectual disability, the other one had global developmental delay. Patients with WBS usually have mild intellectual disability and are usually socially motivated. However, it should be emphasized that WBS has been found to be a risk factor for autism.

\section{Conclusion}

In conclusion, WBS is a complex, genetic disorder characterized by a highly variable phenotype. The most common and significant findings in patients with WBS are dysmorphic facial features and cardiac abnormalities. Furthermore, WBS should be considered in patients with SVAS and concomitant intellectual disability. Additionally, it should be kept in mind that endocrine abnormalities, musculoskeletal, neurologic and psychiatric problems are also frequent in WBS, necessitating a multidisciplinary approach. Early diagnosis is crucial for the management of the syndrome and the prediction of its prognosis.

\section{Ethics}

Ethics Committee Approval: University of Health Sciences Turkey, İzmir Dr. Behçet Uz Pediatric Diseases and Surgery Training and Research Hospital, Clinical Research Ethics Committee approved the study (date: 24.09.2020, number: 2020/13-8). 
Informed Consent: Written informed consent was obtained from all individuals involved.

Peer-review: Externally and internally peer-reviewed.

\section{Authorship Contributions}

Concept: S.G., F.H., Design: B.Ö., S.A., C.Z., Data Collection or Processing: S.G., F.H., C.Z., S.A., Analysis or Interpretation: S.G., F.H., M.M.Y., T.M., Literature Search: B.Ö., S.A., C.Z., Writing: S.G., M.M.Y., T.M.

Conflict of Interest: No conflict of interest was declared by the authors.

Financial Disclosure: The authors declared that this study received no financial support.

\section{References}

1. Ferrero G, Howald C, Micale, et al. An atypical 7q11.23 deletion in a normal IQ Williams-Beuren syndrome patient. Eur I Med Genet 2010; 18:33-8.

2. Committee on Genetics. American Academy of Pediatrics: health care supervision for children with Williams syndrome. Pediatrics 2001; 107:1192-204.

3. Morris CA. Williams Syndrome.. In: Adam MP, Ardinger $\mathrm{HH}$, Pagon RA, et al (eds). GeneReviews ${ }^{\circledR}$ Seattle (WA): University of Washington, Seattle; 1993-2020.

4. Adams $\mathrm{GN}$, Schmaier AH. The Williams-Beuren syndrome-a window into genetic variants leading to the development of cardiovascular disease. PLoS Genet 2012; 8:e1002479. doi: 10.1371/journal.pgen.1002479.

5. Ramírez Velazco A, Domínguez Quezada MG. Atypical deletions in Williams-Beuren syndrome. Rev Med Inst Mex Seguro Soc 2017; 55:615-20.

6. Hedtke T, Schräder CU, Heinz A, et al. A comprehensive map of human elastin cross-linking during elastogenesis. FEBS / 2019; 286:3594-610.

7. Mulik VV, Temple KI, Howe DT. Two pregnancies in a woman with Williams syndrome. BJOG 2004; 111: 511-2.

8. Morris CA, Braddock SR, COUNCIL ON GENETICS. Health care supervision for children with Williams syndrome. Pediatrics 2020; 145:e20193761.

9. Collins RT. Cardiovascular disease in Williams syndrome. Circulation 2013; 127:2125-34.

10. Bird LM, Billman GF, Lacro RV, et al. Sudden death in Williams syndrome: report of ten cases. J Pediatr 1996; 129:926-31.

11. Pham PP, Moller JH, Hills C, Larson V, Pyles L. Cardiac catheterization and operative outcomes from a multicenter consortium for children with Williams syndrome. Pediatr Cardiol 2009; 30:9-14.

12. Wessel A, Gravenhorst V, Buchhorn R, Gosch A, Partsch C), Pankau R. Risk of sudden death in the Williams-Beuren syndrome. Am / Med Genet A 2004; 127A:234-7.
13. Bruno E, Rossi N, Thüer O, Córdoba R, Alday LE. Cardiovascular findings, and clinical course, in patients with Williams syndrome. Cardiol Young 2003; 13:532-6.

14. Eronen M, Peippo M, Hiippala A, et al. Cardiovascular manifestations in 75 patients with Williams syndrome. I Med Genet 2002; 39:554-8.

15. Scheiber D, Fekete G, Urban Z, et al. Echocardiographic findings in patients with Williams-Beuren syndrome. Wien Klin Wochenschr 2006; 118:538-42.

16. Ramírez-Velazco A, Aguayo-Orozco TA, Figuera L, et al. Williams-Beuren syndrome in Mexican patients confirmed by FISH and assessed by aCCH. J Genet 2019; 98:34.

17. Borg I, Delhanty JDA, Baraitser M. Detection of hemizygosity at the elastin locus by FISH analysis as a diagnostic test in both classical and atypical cases of Williams syndrome. I Med Genet 1995; 32:692-6.

18. Eom HJ, Chung HJ, Kim SW, Kim YK. Clinical characteristics of children with Williams Syndrome according to age. I Korean Child Neurol Soc 2010; 18:214-24.

19. Nogueira RJ, Zimmerman LF, Moreno YM, et al. Anthropometric and body-mass composition suggests an intrinsic feature in Williams-Beuren syndrome. Rev Assoc Med Bras 2011; 57:681-5.

20. Palacios-Verdú MG, Segura-Puimedon M, Borralleras $C$, et al. Metabolic abnormalities in Williams-Beuren syndrome. I Med Genet 2015; 52:248-55

21. Kim $\mathrm{YM}, \mathrm{Cho} J \mathrm{H}$, Kang E, et al. Endocrine dysfunctions in children with Williams-Beuren syndrome. Ann Pediatr Endocrinol Metab 2016; 21:15-20.

22. Amenta S, Sofocleous C, Kolialexi A, et al. Clinical manifestations and molecular investigation of 50 patients with Williams syndrome in the Greek population. Pediatr Res 2005; 57:789-95.

23. Sammour ZM, Gomes CM, de Bessa J Jr, et al. Congenital genitourinary abnormalities in children with Williams-Beuren syndrome. I Pediatr Urol 2014; 10:804-9.

24. Morris CA, Demsey SA, Leonard CO, Dilts C, Blackburn BL. Natural history of Williams syndrome: physical characteristics. J Pediatr 1988; 113:318-26.

25. Damasceno ML, Cristante AF, Marcon RM, Barros Filho TE. Prevalence of scoliosis in Williams-Beuren syndrome patients treated at a regional reference center. Clinics (Sao Paulo) 2014; 69:452-6.

26. Mervis CB, Robinson BF, Bertrand J, Morris CA, Klein-Tasman BP, Armstrong SC. The Williams syndrome cognitive profile. Brain Cogn 2000; 44:604-28.

27. Doyle TF, Bellugi U, Korenberg JR, Graham J. Everybody in the world is my friend' hypersociability in young children with Williams syndrome. Am J Med Genet A 2004; 124A:263-73.

28. Klein-Tasman BP, Phillips KD, Lord CE, Mervis CB, Gallo F. Overlap with the autism spectrum in young children with Williams syndrome. J Dev Behav Pediatr 2009; 30:289-99. 